\title{
Comparative Research on Chinese Four Online Learning Platforms
}

\author{
Chen Ying \\ College of Foreign Languages \\ Inner Mongolia University \\ Hohhot, Inner Mongolia, China
}

\begin{abstract}
In 2020, China met at a challenging time when the whole country was battling COVID-19 which was gravely threatening the health, safety, and life of the Chinese people. To secure an early victory against COVID-19, all the schools have online learning with the purpose and task of combining the teachers' teaching resources with online learning resources. The schools take advantage of online learning platforms to develop remote teaching. Online learning platforms are one mode of smart teaching which can both improve the interactive communication between teachers and students and increase the students' interest. Therefore, this paper explains how four popular online learning platforms---Zhihui Shu, Chaoxing Xuexitong, Tengxun Ketang, and Yu Ketang, present a whole procedure for online learning, and gives a comprehensive comparison. The paper also integrates teachers' experiences with lessons to explore practical suggestions and technological improvements. Due to the influence of coronavirus, online learning has become a complement of physical teaching, and in the long run, it will play a vital role in education.
\end{abstract}

Index Terms—online learning platforms, Chaoxing Xuexitong, Yu Ketang, Zhihui Shu, Tengxun Ketang

\section{Introduction}

At the beginning of 2020, China suffered the outbreak of COVID-19.Peoples' lives were seriously affected. In this grave struggle against the epidemic, all the countries made concerted efforts to wage a "a war without smoke". To control the sources of infection, cut off the channels of transmission and resolutely safeguard the well-being of the teachers and the students, all the educational authorities followed the unified command of local central governments and applied effective measures to prevent the spread of the epidemic. Postponing the new semester was one such measure.(website, 2020). Although the teachers and students could not study at their lovely campus, the Chinese educational ministry announced some methods to keep the students' study pace going and promoted a requirement of “class is stopping, but learning and teaching won't stop".(website,2020). Under the order, the country's biggest exercise in remote teaching began.

Nationwide, educational departments did a lot of preparation for online learning. They coordinated the related teaching resources nationally and locally, offered colorful and popular online teaching resources, and guaranteed that the teachers and students could be successful on the Internet. They coordinated the cable TV with Internet resources to realize the advantage of resource sharing.

They ensured that wide coverage especially met the needs of students who lived in the poor rural areas in which some households lacked Internet access. They integrated the features of online learning with the students' actual needs to modify the method, length and teaching plan of physical teaching. Additionally they strengthened the guide for different grades and subjects. They also instructed local teachers to take good advantage of online learning platforms, organized them to conduct course recordings and resource supplies, while mobilizing them to participate in the online guidance and coaching of students. 
Many universities have moved classes online, with little or no time for planning and preparation. Meanwhile, confronting such a wide range of online learning is a huge challenge for online learning platforms. At present, the four popular online learning platforms are Zhihui Shu, Yu Ketang, Chaoxing Xuexitong, and Tengxun Ketang because they have the most users, the most coverage and multiple functions.

The Zhihui Shu platform is a worldwide credit course operating platform which serves nearly 3,000 universities. Billions of students have gained their cross-university credits through it. In recent years, hundreds of colleges established excellent courses and service facilities under the aid of the Zhihui Shu platform. It helped teachers adapt to the development of teaching targets in the new era, assisted them in applying technology to construct new courses, and made the demand for teaching reform come true.

Yu Ketang is a new smart teaching tool that is co-launched by Tsinghua University and the Xuetang Online Learning platform. It is also the latest research result of the Online Learning Center in the Ministry of Education. The Secretary of Education in its evaluation said that Yu Ketang made the cell phone transfer from "the tool for making heads bend down" to "the weapon for making heads look up". He pointed out that Yu Ketang combined online learning with physical learning by using the speaking style of Generation Y, and integrating modern technology.

Chaoxing Xuexitong is a professional mobile learning platform that is based on micro-service. Its goal is to establish course learning, knowledge spreading, and management sharing. Students can participate in their academic coursework and conduct group discussions through Xuexitong App.

Finally, Tengxun Ketang aims at providing professional vocational education that is supported by Tencent Cooperation. It integrates lots of excellent educational institutions and teachers and makes an online class with the purpose of the teachers could teach at home while the students can be interactive instantly. "Tengxun Ketang owns the great and stable majority of users and has a natural gathering effect so it makes a better communication between the teachers and students. Also, it uses QQ as its core client tool to make a great advantage to manipulate the physical class."(Chen Hongpu \& Fan Miaoran,2015,p87)

These four platforms have their advantages and distinct features. They all have played a positive role in the epidemic period by protecting the health of teachers and students, transferring the teaching methods in a timely manner and accomplishing the teaching target of "no-stop in learning". At present, the academic research regarding online learning platforms centers on how to integrate a particular course with one platform, the effects of online learning, or the teacher's role in the changes. However, there is not any comparative research on the practical effects of various platforms. Consequently, the researcher interviewed many teachers in different universities and combined their user experience with students' feedback regarding the actual operating system to provide a comprehensive comparative analysis of the four online learning platforms. The hope is to offer references for future teaching design and improvement of online learning platforms to support the teachers who will teach online in the future.

\section{Online Learning Preparation}

\section{A. Registration}

Thanks to the fast development of the internet, mobile equipment has become a necessity in people's daily lives. Therefore, every online learning platform offers two ways of installation which can be done via a computer and a cell phone. They make the most of the cell phone to make it serve for education, transforming it from a tool of communication and entertainment "to make it realize the information education and education optimization." $(\mathrm{Lv}$ Shuiping, 2019, p117)Whether by computer or cell phone, registration is always the first step. Zhihui Shu and Chaoxing Xuexitong connect with the university's educational administration platform, so teachers and students use their school ID numbers to register in the Zhidao APP and Xuexitong App; then their online learning is ready. 
In contrast, the Zhihui Shu platform has a requirement for the browser, so it is better to use Firefox or the Google browser. Tengxun Ketang needs users to download the installation software and its App from the Internet, for it does not offer the match with a school ID. Teachers and students register by their cell phone numbers and then begin their study.

Yu Ketang is comparatively easier in registration. It can be inserted into a Powerpoint presentation and perfectly combines Wechat with Powerpoint. Teachers and students can just use it in Wechat to save any trouble downloading other software or applications. Wechat, a messaging app, is the most popular social media tool in China.The latest survey claims that Chinese people spend five hours per day on Wechat, with college students the most faithful supporters. Their communication, life, and entertainment all encompass Wechat. Yu Ketang clearly observesthe college students' strong dependence on Wechat and then puts its online learning platform in Wechat. It is very convenient for the students to engage in learning through reminders from Wechat.

At present, the educational app plays a vital role in the transformation between the teaching mode. Its purpose is to develop by "specific teaching target and content, embody a kind of teaching strategy, and running through the mobile to realize the interaction study between the teachers and students."(Hang Houwei,Zhou Zhengqing \& Min Yingying, 2019, p30)

\section{B. Establishing the Course}

Generally speaking, not all the courses have a prepared and systematic resource, and not all the teachers own their course reservoir either. Each course, such as College English, College Computers, Introduction to the Basic Principles of Marxism, and so on, belongs to the basic courses in a university which can directly apply for the online courses from each online learning platform. The teaching can be conducted through students' self-learning and teachers' online aiding. If the teacher does not have a completed course resource, he also can use a well-developed online MOOC, when available, as his teaching material or combine it with his teaching content.

Therefore, creation of teachers' teaching resources is the top priority. For those teachers who neither have personal resources nor an online MOOC, the fastest way to realize online teaching is to adopt the "Model Teaching Pack" from the Chaoxing Xuexitong platform. It easily creates an online course through only "one-key" operation. Its main purpose is to satisfy the multiple needs of teachers in their teaching preparation, and to ease their pressure and workload. The teaching content in the "Model Teaching Pack" is provided by famous experts in universities. Teachers can re-edit it, adapting it to their particular courses. It is simple for the teacher to just type, "New Course" on the cellphone and choose the option of "Model Teaching Pack" and begin searching. If there is a relevant course, then the teacher can addit to his course. However, at present there are only parts of courses that can be used while others are under development.

ChaoXing Xuexitong offers another function that is called "Super-speed Class". The teacher inputs the name and subject of the course; then Xuexitong will automatically create the teaching unit including the teaching period and class hours. The teacher also can set his teaching plan. After that, he records the teaching content into "Super-speed Class" by using the method of "Powerpoint+audio." He could add different kinds of materials, even tests.Then the platform forms a completed online course and saves it in the Cloud. In this way, it preserves the course's authenticity to the greatest extent.

The Zhihui Shu platform also provides an index to its professional database to teachers who do not have online teaching resources at hand, which is called "Online Golden Class". The teacher can directly use the resources from the database to form his class, with the expectation that the teacher's university applies to enter the Professional Sharing Union of Chinese Universities in advance and its membership is active.

\section{To Optimize Personal Teaching Materials}


For teachers of specialized courses with completed teaching materials from in-person classes wanting to adapt them to online learning, they may just need to optimize and enrich their teaching plans. Since all these online learning platforms have a pattern design for different courses, the teacher could rearrange his teaching materials to adapt to an online format. For example, he could categorize his teaching materials by "Chapter 1" or "Unit 1" from the textbook. Other options would be to organize by the teaching timetable such as "Week 1", "Week 2" or the study technique: "Preview," "Lessons," and "Review Exercises". Categorizing by teaching materials or tasks "audio," "oral practice," and "research papers" is yet another possibility. Through the subdivision of the teaching materials and the explanation on the front page of the platform, students would understand the teacher's requirements and learning targets. After organizing categories, the teacher can enrich his teaching plan by adding other teaching resources, such as audio and video lessons or the MOOC website.

The next step is to upload the teaching materials to the platform. The teacher can upload audio, video, compacted files, word files, and more through a computer or laptop, but not so much can be done from the cellphone. There are some limitations for the files. For example, Zhihui Shu demands that the size of a single file is no more than $2 \mathrm{G}$. The teacher also can upload it to the online resource database. Similarly, he could subdivide the teaching materials by practice or discussion and then share it with the students or team members teaching the same class. In this way the teacher will form his personal database.

\section{Posting the Course and Inviting the Students}

The teacher sends the course invitation to the students after posting it to the platform. Zhihui Shu and Chaoxing Xuexitong are both based within the university's educational administration system, so the teacher just posts the course's unique QR code to students, who will enter into the online classroom by scanning it. Tengxun Ketang is registered through the teachers' and students' phone numbers; the teacher only needs to send the course's link or QR code to the students who will begin their study through Wechat, QQ, or computer. Yu Ketang is connected with Wechat through which the students will get a reminder after the teacher posted his course.

\section{ONLINE EDUCATION}

Although online learning is not a new thing in China, until recently it was only a complement to traditional teaching. At present, due to COVID-19, online learning is becoming the main method of learning, arousing multiple anxieties among teachers that include the transformation of the teaching role, discomfort with the technology, and the doubt about the teaching efficacy. These are natural feelings because though traditional teaching has been linked with multimedia technology during past years, the Powerpoint preparation occurred before the classroom delivery. Teachers may take comfort in considering the improvements possible through online delivery. With face-to-face teaching, there is distance between the teaching platform and the last row, while via the screen of the cell phone or the computer, every student has a front row view. The teacher-student relationship becomes "less hierarchical." There are no differences in learning due to a students' location in the classroom anymore. The teacher's voice is audible to all students, the words on the Powerpoint are visible to all, and the teaching speed is less relevant because now students can stop the video or audio at any time. Online learning overcomes many of the disadvantages of in-person classes. Each online learning platform offers multiple ways for teaching.They can effectively bring teachers and students together, motivate students' enthusiasm and boost the interaction between them.

\section{A. Powerpoint + Audio}

As previously mentioned, the students can start their individual study after the teacher has posted his courses online. Then the teacher becomes responsible for answering students' questions. Considering the difficulty of distance learning, most teachers choose to include an audio explanation on each page of their Powerpoint. 
The audio explanation can be live audio, which means the teacher broadcasts his teaching live at an online class. Another way is to record the audio explanation in advance during the Powerpoint preparation, just like the "Super-speed Class" mentioned earlier. Yu Ketang also provides the capability for the teacher toembedsixty second audio explanations within a slideshow. With the audio saved to each page, the students can watch the Powerpoint while listening to the teacher's instruction simultaneously.

The "Meeting Class" feature in the Zhihui Shu platform supports live streaming which is delivered by the teacher, but the teacher and students only can hear each other rather than "meet" face-to-face. The latest version will support interaction between the teacher and students. The teacher may choose students' names and click their individual microphones, allowing up tosix students to talk at one time. Unfortunately, the "Meeting Class" feature does not allow a course session to be saved for review, nor can it be conducted via cell phone.

\section{B. Video live-streaming}

Chaoxing Xuexitong requires clients to install the Chaoxing Live Program software first if the teacher wants to have live broadcasting. Then they may access it through the Xuexitong App. It can broadcast to many classes simultaneously, and the students may review the course video at any time. However, the camera only shows the teacher in front instead of showing the Powerpoint alongside. Using this method, the students may feel like they are talking with their teacher face-to-face, which is a better approach for answering questions and solving assigned problems. Chaoxing Xuexitong offers a second way of live streaming using "camera + word/Powerpoint file". The teacher sets up the topic and then determines the particular date for video live streaming. After uploading the teaching files to the Chaoxing platform and sharing the invitation code, the students will watch the scheduled video. The third way is through "screen-sharing" for the teacher who wants to share his pictures, slides or videos, but students can only see the teacher's computer screen, not the teacher.

According to the survey, teachers are less likely to use the live video broadcasting, because they are concerned that the students will be distracted if the teacher's video instruction and the Powerpoint file appear on the screen at the same time. When live broadcasting, it is advisable to conduct a trial lesson in advance to make sure the live broadcasting will proceed smoothly. The teacher should check whether the teaching files operate successfully and whether the microphone and camera are in good condition. Additionally, the teacher should log in to the online learning platform fifteen minutes early, to avoid network congestion.

\section{Iv.Class Interaction}

In face-to-face teaching, the teacher has difficulty interacting with every student due to the number of students and the demands of instruction. Typically the teacher has interaction with the students who are active in answering questions, which puts others at risk of being ignored. Considering all these problems, the online learning platform supplies rich tools to facilitate student participation.

\section{A. Attendance}

Taking attendance is a bothersome task during physical teaching because the teacher must read every student's name one by one. In contrast, online learning platforms offer many options, including QR attendance, gesture designing attendance, position attendance, and random attendance. With a press of a button on a cell phone, attendance can be finished in a couple of minutes, no matter how many students in a class. It also prevents present students from signing in for truant students. Through the multiple options, teaching time is effectively used, and the class atmosphere is beingactivated greatly.Teachers' feedback indicated thatat times students had been present, but the teacher could not see the information in time which resulted in mistakes in the overall numbers. However, the teacher can keep teaching because the students' attendance data is saved, though the reminder to the teacher may be delayed due to an internet jam. 
For that reason, the teacher could prolong the time of taking attendance to avoid the rush hour, even changing the attendance time to the middle or end of class.

\section{B. Instant Response in the Online Class}

The primary concern for the teacher is whether students can relate to the course or not. Although online learning can not provide the teacher with a visual response from the students' facial expressions as is the case in the physical classroom, students can offer their instant responses to the teacher using the online platforms.

Take Yu Ketang as an example. The students can watch the teacher's Powerpoint through Wechat at any time. On each page of Powerpoint, the platform offers two buttons: "don't understand" and "got it" for the students to give a prompt response. Meanwhile, Yu Ketang considers the students' self-esteem so those responses are anonymous, dispelling anxiety and allowing them to express their confusion freely. Also, the students can use the "Say More" function to give a further explanation about their questions, and then the teacher may give an expanded explanation.

Another interactive function in Yu Ketang is "barrage," which is a commentary subtitle that appears on the screen during a video. The "barrage" gives space for students to ask questions, including those who may have been too shy in the physical classroom. Through "barrage," students have more interaction with each other, and the teacher's understanding of student comprehension increases. Another Yu Ketang interactive function is "wordle," a concept invented by Rich Gordon, an associate professor in the Department of Journalism at Northwestern University. Wordle visually represents the "keywords" frequently appearing ininternet texts in the shape of a "keywords cloud." Yu Ketang applies it to online learning by generating a "wordle" with acompilation of comments from the students' "barrage." Pointing to individual words within each "wordle" will show the number of students who mentioned it; clicking on the link to the specific page on Powerpoint. "Wordles" offer students a unique interaction opportunity.

Tengxun Ketang accomplishes interaction differently by employing the students' microphone. The student who wants to comment or ask a questioncan click the "raise hand" button and speak to the class, after the teacher's approval. "As teachers break ground on new ways of teaching students, it is important to engage them in this process by encouraging their feedback on the success of online interaction." (John D.Loike \& Marian Stoltz-Loike, 2020)

\section{Online Tests and Evaluation}

Assessment is a vital part of the teaching process, through which the teacher will grasp the students' level and be able to properly prepare for later lessons. On the online learning platform, the teacher may assign different forms of tests, such as classroom quiz, monthly test, or mid-term test.

In traditional assessments, the students generally wrote upon exercise booklets which the teacher corrected one by one and recorded the scores. If the teacher teaches many classes, the correcting load is daunting. Online learning platforms apply technology to make it simple for correcting assignments and problem sets. Additionally, since the assignments are online, organization is simplified.

Yu Ketang launches a "flash answering" form that makes the classroom quiz easy to accomplish. After the teacher has finished creating the test, he can choose to post it directly or schedule it for a given time. The platform will automatically correct and post the score for student viewing, indicating the correct answers to objective questions. Then the teacher will receive a final report shown in a bar graph depicting the number of students who gave the right answer per question. Yu Ketang also selects a "good student" and an "endangered student" to help the teacher better manage the class. Yu Ketang also has a subjective questions test with a collaborative feature. The teacher posts a question to a group of students who canchoose word or picture answers individually and ultimately come to a group consensus which they submit to the teacher. 
Zhihui Shu has many ways for the teacher to assign the schoolwork. He could create the questions himself or import and edit the questions in Zhihui Shu's database. The teacher establishes the due date and score points, and then the students will receive a reminder on their cell phones. After the deadline, the platform will collect all the assignments, including incomplete ones, and score them. To motivate those students who have not finished their assignments, the teacher can send them an "urgent" message. There is also an option for a teacher to return an incomplete or unqualified assignment for a "re-do". When all the assignments have been corrected, the teacher can check the analytical report, which includes detailed information about each student.

If the teacher uses Yu Ketang for the assignment, all his pre-prepared exercises can be directly transferred to the platform in multiple-choice, blank filling, or discussion form. After receiving the teacher's corrections, students can save their errors or improvement suggestions in the "mistake collection," a convenient way for them to review and practice.

Each online learning platform offers excellent choices for learning evaluation. There are data analysis reports and objective presentations with bar graphs or pie charts, so the teacher can clearly study attendance rates, trends in question difficulty, and discussion posts. The comprehensive data analysis greatly aids the teacher in following the students' learning pace and results in timely detection of teaching problems, leading to improvement in teaching methods.

\section{Conclusion}

At such a crucial time to curb the spread of COVID-19, all the universities and colleges must answer the call from the Ministry of Education by developing online learning that accomplishes high-quality teaching. For each teacher, it is both a challenge and an opportunity. Zhihui Shu, Yu Ketang, Tengxun Ketang, and Chaoxing Xuexitong can accomplish the teaching task smoothly and have distinct and affiliated functions. Teachers' feedback indicated that if all the students registered in the online learning platform sticking to the timetable suggested by the syllabus, there would be network congestion which would lead attendance errors or even the inability to enter into the online class. Therefore, it is advised that the teacher hands out his teaching files, textbooks, reference books or MOOC linkage to the students in advance, and give them enough time to follow the online teaching video or audio, allowing students to arrange their study time according to their actual situation. Another observation suggests that the students struggle to finish the assignments such as notes, group discussions, or papers before the deadline. Thus a focus on process management and strict assignment and attendance requirements is critical. Only in this way can the students' passive learning be converted to active learning.

The coronavirus is causing massive disruption to education in China. "Study must not stop" and "education + Internet" are not just slogans, but crucial practices to continue learning during the pandemic. In-person classes in most universities moved online.During several months, the teachers and the students adapted from strangeness to acquaintance. Meanwhile the online learning platforms kept upgrading and improving their system to offer more simple and convenient ways of learning. In the future the design of the online learning platform should embody the diversity of the courses, fully satisfying the individuality of the students and the structure of the syllabus to meet the students' and teachers' needs. We hope that the temporary transition of physical education to an online format will help reduce the spread of COVID-19. In the long run, successfully adopting an innovative way to facilitate learning will be invaluable for education.

\section{References}

Chen Hongpu \& Fan Miaoran.(2015). Thinking and Enlightenment on Operation Mode of Tencent Classroom Online Education. Modern Educational Technology, vol 25, 86-92.

Hang Houwei, Zhou Zhengqing \& Min Yingying.(2019). Marketing Predication about the Educational App. Journal of Brand Research, vol. 15, 30-31. 
John D.Loike \& Marian Stoltz-Loike. (2020). Making Online Teaching a Success. The Scientist. Web TranscriptionTool.

https://www.the-scientist.com/news-opinion/opinion-making-online-teaching-a-success-67290(accessed25/4/2020). Lv Shuiping.(2019). Research on the Course Construction between Chaoxing Online Network and Xuexi Tong. Education Modernization, vol.97, 117-118.

Web Transcription Tool. http://www.moe.gov.cn/jyb_xwfb/s5147/202002/t20200203_417488.html (accessed 2/3/2020).

Web Transcription Tool. http://www.gov.cn/zhengce/zhengceku/2020-01/28/content_5472571.htm (accessed $1 / 3 / 2020)$.

Ying Chen is a lecturer in College of Foreign Languages of Inner Mongolia University(IMU), and received her Ph.D from Tianjin Normal University.As a visiting scholar in St. Cloud State University, USA, she has accomplished her research with American scholars and gained a reputation for her hard working. As the host of Sinclair Lewis Society, her lectures received a great feedback from the international participant. Her book Sinclair Lewis and American Popular Culture won the $7^{\text {th }}$ Government Award for Excellent Achievement of Philosophy \& Social Sciences of Inner Mongolia in 2018. Her research focus on the American literature and college English teaching. 